Available online at www.eccomasproceedia.org

Eccomas Proceedia COMPDYN (2021) 1097-1111

ECCOMAS

Proceedia
COMPDYN 2021

$8^{\text {th }}$ ECCOMAS Thematic Conference on Computational Methods in Structural Dynamics and Earthquake Engineering M. Papadrakakis, M. Fragiadakis (eds.) Streamed from Athens, Greece, 28 - 30 June 2021

\title{
ASSESSMENT OF THE RESPONSE ENVELOPE OF REINFORCED CONCRETE MEMBERS WITH DIFFERENT FAILURE MODES
}

\author{
Mariano Di Domenico ${ }^{1}$, Paolo Ricci ${ }^{1}$, and Gerardo M. Verderame $^{1}$ \\ ${ }^{1}$ Department of Structures for Engineering and Architecture, University of Naples Federico II \\ Via Claudio 21 - 80125 - Naples, Italy \\ e-mail: \{mariano.didomenico, paolo.ricci, verderam\}@unina.it
}

\begin{abstract}
The expected lateral response of reinforced concrete $(R C)$ elements strongly depends on their failure mode. Code-conforming $R C$ members are supposed to exhibit a flexural $(F)$ ductile failure, with complete exploitation of their post-peak displacement/deformation capacity. However, substandard RC elements, which are typical of existing structures, may undergo a shear failure after yielding (FS) or even before yielding (S) of longitudinal reinforcement. In this case, the element is classified as "shear-sensitive" and may be characterized by an abrupt collapse after the attainment of the peak load-capacity, with a fast loss of lateral load-bearing capacity up to the onset of the progressive reduction of the axial load-bearing capacity. This condition may trigger structural collapse, as also shown from surveys of damages due to strong earthquakes in past and recent times. So, the determination of the failure mode of RC members is paramount for a reliable assessment of the seismic safety of structures.

In general, static criteria are applied to pre-classify the expected failure mode of $R C$ members and their response backbone is defined dependently on the determined failure mode. However, a comprehensive approach for modelling, with a unique set of predictive equations, the response envelope of RC members without pre-determining with a deterministic approach their failure mode is missing.

In this paper membership functions are defined to determine for $R C$ columns the possibility that they exhibit an F, an FS, or an S failure. A set of basic predictive equations are defined, based on experimental data, to define a multilinear response envelope. The proposed equations may be combined with membership functions to use a unique set of equation able to reproduce the behaviour of RC columns with different expected failure modes.
\end{abstract}

Keywords: RC element, existing, seismic assessment, failure mode, response envelope, model. 


\section{INTRODUCTION}

In the last decades, one of the trends of research in the structural engineering field is aimed at providing robust and reliable tools for nonlinear modelling of structural members. This is an essential step towards a complete implementation of a performance-based approach for the seismic design and assessment of structures in technical codes and current practice.

In Reinforced Concrete (RC) structures, primary elements may have a different lateral nonlinear response dependently on their failure mode. If, under lateral loads, the element can first yield and then exploit its entire ductility capacity (as shown in Figure 1), its failure mode is ductile and flexure-controlled. Such a kind of element is defined flexure-critical, the name of its failure mode is usually abbreviated with an " $F$ ", the element itself can be defined as an " $F$ element". If, under lateral loads, the element cannot exploit its entire ductility capacity (as shown in Fig. 1), the element is defined shear-critical, since the ductile response of the element is prematurely interrupted by the occurrence of a shear failure. Two conditions may occur: if the element is anyhow able to yield, the failure mode is defined "FS", since it is first governed by flexure (the element can yield), then by shear (the element cannot attain its ductility capacity since a shear failure occurs first); if the element is not able even to yield, since the shear failure occurs before yielding, the failure mode is defined " $\mathrm{S}$ ", since it is governed by shear. Also in this case, elements experiencing an FS failure mode are called "FS elements", while elements experiencing an S failure mode are called "S elements".

Also from Figure 1, it is clear that RC members with different failure modes have different lateral response. For this reason, the assessment of the expected failure mode (or "classification of the failure mode") is essential to correctly model the nonlinear response of each member and, so, to obtain a reliable prediction of the structural performance. This is of paramount importance especially when dealing with nonlinear modelling and seismic capacity assessment of existing $\mathrm{RC}$ buildings.

In the literature, different approaches have been proposed for the classification of the failure mode of structural members. Some of them have been also introduced in building codes. The first approach to the classification of failure mode was described by Priestley et al. [1] based on ATC-6 [2] provisions. First, it is stated that the shear strength of a RC structural members is maximum when the element is in the elastic field; such a strength decreases at increasing ductility demand due to the damage of the element, up to a minimum (or "residual") value. Similarly to what is represented in Figure 1, the failure mode is $\mathrm{F}$ if the shear force corresponding to flexural strength is less than the residual shear strength; the failure mode is $\mathrm{S}$ if the shear force corresponding to flexural strength is more than the initial shear strength; otherwise, the expected failure mode is FS. This approach for the classification of structural members' failure mode, with consistent nonlinear modelling of the lateral response of these structural members, has been adopted for nonlinear time-history analyses on case-study existing RC buildings in [3]. However, different authors, based on experimental evidences, highlighted that the ratio between the shear strength of a member and the shear demand in equilibrium with its flexural strength cannot completely explain the observed failure mode of RC elements.

For example, Zhu et al. [4] proposed, based on experimental data, a classification method distinguishing F and S elements; FS elements are mostly included among S elements. According to this method, first the transverse reinforcement ratio should be calculated. If this ratio is lower than 0.002 , the element is classified as S. Otherwise, the shear span-to-dept of the cross section ratio and the ratio between the plastic shear demand and the shear strength by Sezen and Moehle [5] are calculated. If the first ratio is lower than 2 or the second ratio is higher than 1.05 , the element is classified as $\mathrm{S}$. Otherwise, it is classified as F. 
Ghannoum and Matamoros [6] and Ghannoum [7] proposed a modification to the method of classification of the failure modes of columns due to splice deficiency reported in ASCE/SEI 41-13 [8]. The proposal has been implemented in ASCE/SEI 41-17 [9] together with a proposal for the definition of the significant points of the lateral response of $\mathrm{RC}$ columns depending on the potential failure due to splice deficiency.

Based on experimental data, Hua et al. [10] proposed a classification method of the failure mode of RC members based on the concept of likelihood of shear failure. The probability of shear failure is calculated based on a demand-to-capacity ratio in which the capacity is evaluated through a proposed shear strength model.

Based on experimental data, Ma and Gong [11] proposed the calculation of a factor $\omega$ depending on geometric and mechanical characteristics of the RC columns. Based on the value assumed by the factor $\omega$, it is possible to establish the expected failure mode of the element. One of the most significant advantages of this approach is that, differently from other methods, the prediction of the failure mode is independent on the specific shear strength model adopted. A similar approach will be introduced also in this study.

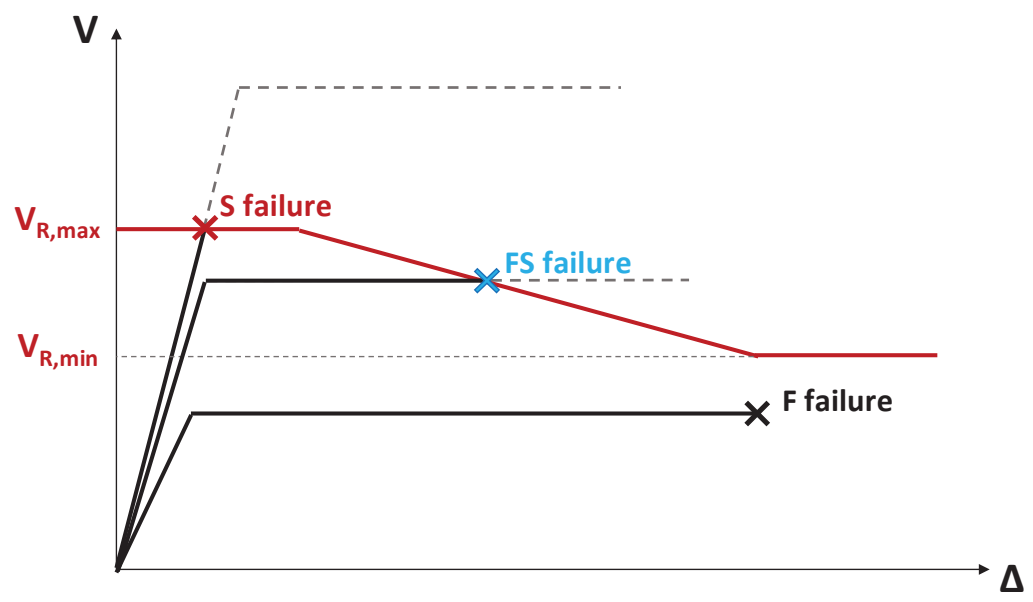

Figure 1: Illustrative sketch of the expected lateral response of F, FS, and S members.

One of the shortcomings of most of these approaches is their deterministic outcome. In this work, an empirical approach based on fuzzy theory is proposed for the assessment of the failure mode of RC members. In other words, the proposed approach aims at assigning to each generic RC structural element the "possibility" (expressed through a scalar between 0 and 1) of being "member" of the sets of F, of FS and of S elements. This scalar is calculated via membership functions which are defined for each of the three sets/failure modes. The definition of a "continuous" classification of the failure mode of structural elements is a preliminary step towards the assessment of the lateral response of RC members without an explicit pre-classification, but by means of an implicit modification of the expected ductile response backbone of the element by using the proposed membership functions. Based on the same experimental database, empirical equations are proposed for the assessment of the expected response envelope of ductile elements.

\section{EXPERIMENTAL DATABASE}

The definition of the proposed approach for the direct assessment of RC elements' failure mode is based on the experimental data collected in the ACI 369 Rectangular Column Database [12], which will be briefly named "ACI database" in the following. 
The ACI database is constituted by 326 cyclic tests of rectangular RC columns. In this work, only cyclic tests of rectangular-reinforced columns are considered. All specimens are characterized by the presence of deformed (i.e., ribbed) longitudinal rebars, while transverse reinforcement may be realized with deformed or plain bars. For each specimen, the following data are reported:

- Material properties (for concrete, longitudinal and transverse reinforcement);

- Column geometry (for the overall column, longitudinal and transverse reinforcement);

- Confinement details (i.e., the configuration of transverse reinforcement);

- Test configuration details (i.e., how the lateral load was applied on the specimen);

- Test results in terms of observed failure mode, significant values of force and displacement, force-displacement loops (if available).

Since the assessment of the failure mode is the core issue of this work, it is worth mentioning how the definition of the failure mode was performed by the Authors of the database. Two approaches are considered for failure mode classification: the first one is consistent with the approach adopted by PEER in [13] and is more based on the "observed" response of the specimens; the second, which is more "practice-oriented", is based on the assessment of transverse reinforcement detailing and on the ratio between the plastic shear demand and the expected shear capacity. The discussion presented in this paper is based on the first classification approach, i.e., the one consistent with PEER [13], since it is independent of the assessment of shear strength by means of a specific shear capacity model. In fact, consistently with the PEER approach, a first distinction is made between shear-sensitive and non-shear-sensitive members. If the Authors of each experimental test reports the occurrence of shear damage for a certain specimen, the element is classified as "shear critical". Otherwise, it is classified as "flexure critical" and the assigned failure mode is F.

Among Shear Critical elements, a mixed analytical/empirical approach is adopted to distinguish FS and $\mathrm{S}$ elements. First, for each specimen, the maximum lateral force attained $\left(\mathrm{F}_{\text {eff }}\right)$ is evaluated. Then, the theoretical maximum force corresponding to the attainment of a maximum strain in concrete equal to $0.4 \%\left(\mathrm{~F}_{0.004}\right)$ is calculated. In addition, based on the experimental response of the specimen, the ductility capacity $\mu_{\text {fail }}$ is calculated by assuming as failure displacement the one associated with a force capacity equal to 0.80 times $\mathrm{F}_{\text {eff }}$ on the softening branch of the force-displacement response. If $\mathrm{F}_{\text {eff }}$ is lower than 0.95 times $\mathrm{F}_{0.004}$ or $\mu_{\text {fail }}$ is equal or lower than 2, the Shear Critical element is classified as S. Otherwise, it is classified as FS.

Among the 326 tests collected in the database, only those for which all the significant geometric, mechanical and response parameters were available have been used for this study. In addition, only "completely cyclic" tests were considered: in other words, test with monotonic loading before and/or after yielding were excluded. In addition, columns with spliced reinforcement were excluded since they can undergo a premature failure due to insufficient anchorage length, as shown, for example, for the specimens by Melek and Wallace [14] that are included in the original ACI dataset but are not considered for this study. Hence, a subset of the ACI database constituted by 260 tests is considered in this work. In this reference subset, hereinafter named "collected database", 156 tests are classified as F (60\% of the database), 69 tests are classified as FS (26\% of the database), 35 tests are classified as S (14\% of the database). Despite other databases considering shear-sensitive RC members have been collected including a larger amount of S tests (e.g., $[15,16,17]$ ), it was preferred to adopt ACI database since it includes also F elements, which is fundamental for the scope of this study; on the other hand, "merging" $\mathrm{F}$ elements from ACI and FS/S elements from other databases was excluded, in order to use 
data associated with RC columns whose failure mode has been classified with a unique and consistent approach.

The tests collected in the reference subset are characterized by $0 \leq v$ (axial load ratio) $\leq 0.90$, $13 \leq \mathrm{f}_{\mathrm{c}}$ (compressive strength of concrete) $\leq 118 \mathrm{MPa}, 318 \leq \mathrm{f}_{\mathrm{yl}}$ (yielding stress of longitudinal rebars) $\leq 587 \mathrm{MPa}, 249 \leq \mathrm{f}_{\mathrm{yw}}$ (yielding stress of transverse rebars) $\leq 1424 \mathrm{MPa}, 0.0068 \leq \rho_{1}$ (longitudinal reinforcement ratio) $\leq 0.0694,0.0006 \leq \rho_{\mathrm{w}}$ (transverse reinforcement ratio) $\leq$ $0.0321,0.11 \leq \mathrm{h} / \mathrm{L}_{\mathrm{s}}$ (cross section height-to-shear span aspect ratio) $\leq 0.87,0.11 \leq \mathrm{s} / \mathrm{d}$ (transverse reinforcement spacing-to-effective depth of the cross section ratio) $\leq 1.27$. In addition, the experimental response loops of specimens were corrected, if necessary, in order to remove the spurious effect given by geometric non-linearity (i.e., P- $\Delta$ effects) and, so, consider only mechanical sources triggering the post-peak softening. The correction has been performed in order to lead back the experimental response of the selected specimens to "Case I" according to [13].

The database is described more in details in [12].

\section{ASSESSMENT OF FAILURE MODE VIA MEMBERSHIP FUNCTIONS}

In this work, the collected database is considered as the union of fuzzy sets [18]. A fuzzy set is a collection of objects with a certain membership. More specifically, each specimen can be member of the "F elements" fuzzy set, of the "FS elements" fuzzy set and of the "S elements" fuzzy set. In other words, it is possible to define, for each specimen, if it is certainly F, certainly FS or certainly $\mathrm{S}$.

However, when dealing with a generic structural member belonging to a structure, it is not always possible to define with certainty if it will behave as an F element, or as an FS element of as an S element. In this case, a membership function allows expressing the possibility [19] of that element of behaving as an F element, as an FS element and as an S element. In other words, the membership function for $\mathrm{F}$ elements, $\mu_{\mathrm{F}}$, expresses with a number ranging from 0 to 1 , the possibility that a certain structural member belongs to the set of $\mathrm{F}$ elements; the same applies for the membership function for FS elements, $\mu_{\mathrm{FS}}$, and for the membership function for $\mathrm{S}$ elements, $\mu_{\mathrm{S}}$. Of course, it is certain that a member will be part of one of the three sets. So, the sum of the values assumed by the three membership functions for a certain structural element should always be equal to 1 .

The membership function can express the possibility of a certain structural member of being part of a certain set as a function of a predictive parameter (or of more predictive parameters) that represents the structural member characteristics. Of course, the significant characteristics of the structural member (i.e., those that can define a potential domain - also called support for the membership function) depend on the nature of the membership function itself. For example, since the membership functions that are defined in this work are related to the concept of failure mode, it is expected that parameters like the axial load ratio or the amount of longitudinal and transverse reinforcement may be appropriate as predictors. Section 3.2 is dedicated to the definition of the most appropriate predictive parameter(s).

Consider now to have defined a certain predictive parameter $\mathrm{x}$. Hence, the membership functions are expressed as $\mu_{\mathrm{F}}(\mathrm{x}), \mu_{\mathrm{FS}}(\mathrm{x}), \mu_{\mathrm{S}}(\mathrm{x})$. The values assumed by the membership functions are set based on the experimental data reported in the collected database. The procedure adopted to define the shape of the membership functions is reported below, with reference to the illustrative sketch reported in Figure 2. 


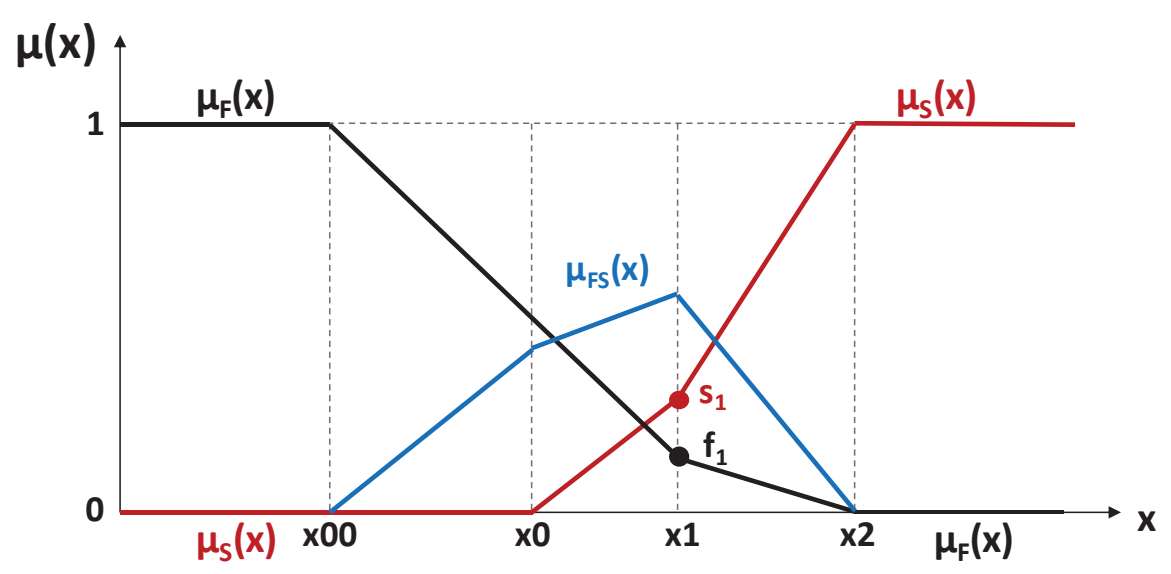

Figure 2: Illustrative sketch of the adopted membership functions.

1. Membership functions are assumed as piecewise linear;

2. The value $\mathrm{x}_{00}$ of the predictor parameter is set. It is defined in order to have $\mu_{\mathrm{F}}\left(\mathrm{x}_{\mathrm{X}} \mathrm{x}_{00}\right)=1$. In other words, if the predictor $\mathrm{x}$ is lower than or equal to $\mathrm{x}_{00}$, it is assumed that certainly the structural member will exhibit an $\mathrm{F}$ failure mode. The value of $\mathrm{x}_{00}$ is obtained from the collected database as the maximum value of $\mathrm{x}$ below which no FS or S failure is observed;

3. The value $\mathrm{x}_{0}$ of the predictor parameter is set. It is defined in order to have $\mu_{\mathrm{S}}\left(\mathrm{x} \leq \mathrm{x}_{0}\right)=0$. In other words, if the predictor $\mathrm{x}$ is lower than or equal to $\mathrm{x}_{0}$, it is assumed that certainly the structural member will not exhibit an $\mathrm{S}$ failure mode. The value of $\mathrm{x}_{0}$ is obtained from the collected database as the maximum value of $\mathrm{x}$ below which no $\mathrm{S}$ failure is observed;

4. The value $x_{2}$ of the predictor parameter is set. It is defined in order to have $\mu_{S}\left(x_{2} \geq x_{2}\right)=1$. In other words, if the predictor $\mathrm{x}$ is higher than or equal to $\mathrm{x}_{2}$, it is assumed that certainly the structural member will exhibit an $\mathrm{S}$ failure mode. The value of $\mathrm{x}_{2}$ is obtained from the collected database as the maximum value of $\mathrm{x}$ above which no $\mathrm{F}$ or FS failure is observed;

5. The membership function for FS failure mode $\mu_{\mathrm{FS}}(\mathrm{x})$ is assumed equal to $1-\mu_{\mathrm{FS}}(\mathrm{x})-$ $\mu_{\mathrm{S}}(\mathrm{x})$;

6. Being $\mathrm{f}_{1}=\mu_{\mathrm{F}}\left(\mathrm{x}_{1}\right)$ and $\mathrm{s}_{1}=\mu_{\mathrm{S}}\left(\mathrm{x}_{1}\right)$, the values of $\mathrm{x}_{1}$ (which is between $\mathrm{x}_{0}$ and $\left.\mathrm{x}_{2}\right), \mathrm{f}_{1}$ and $\mathrm{s}_{1}$ are set after an iterative procedure aimed at obtaining the "best performance" for the membership functions, i.e., the set of $\mathrm{x}_{1}, \mathrm{f}_{1}$, and $\mathrm{s}_{1}$ values for which the adopted membership functions are able to correctly predict the failure mode of the specimens of the collected database in the highest number of cases.

In a previous work [20], different potential predictors were already evaluated, namely the axial load ratio, the aspect ratio and the ratio between the mechanical ratio of longitudinal and transverse reinforcement. In general, as also reported in section 1, the distinction between shear critical and flexural critical structural members can be performed via a "static" approach by comparing shear demand at yielding $\mathrm{V}_{\mathrm{y}}$ (i.e., the one in equilibrium with the yielding moment acting at the base of column) and the shear demand at maximum $\mathrm{V}_{\max }$ (i.e., the one in equilibrium with the maximum moment acting at the base of column), with the shear resistance of the column, $\mathrm{V}_{\mathrm{R}}$. A member is flexure critical if $\mathrm{V}_{\max }$ is lower than the minimum value of $\mathrm{V}_{\mathrm{R}}$; otherwise, it is shear-critical. It should be considered that at increasing axial load ratio, both the maximum moment (i.e., $V_{\max }$ ) and the shear resistance $V_{R}$, first increase and then decrease. So, 
a specific trend for the frequency of each failure mode at increasing $v$ is not expected. In fact, in [20], it was observed that the axial load ratio alone is not a good predictor of the failure mode. A better performance is obtained by considering as predictor the aspect ratio and the ratio between longitudinal and transverse reinforcement mechanical ratios. However, it was observed that the best performance was obtained by adopting as predictor a combination of these two parameters, as shown in Equation 1.

$$
x=\frac{h}{L_{s}} \frac{\omega_{l}}{\omega_{w}}=\frac{h}{L_{s}} \frac{s}{d} \frac{A_{s l} f_{y l}}{A_{s w} f_{y w}}
$$

Since the predictive parameter $\mathrm{x}$ has been chosen, it is possible to define the membership functions. Based on the collected database, it is observed that:

1. For $\mathrm{x}$ lower than or equal to 0.75 , only $\mathrm{F}$ failures are observed. Hence, $\mathrm{x}_{00}$ (see Figure 2) is assumed equal to 1 ;

2. No $\mathrm{S}$ failure is observed for $\mathrm{x}$ lower than or equal to 1.50 . Hence, $\mathrm{x}_{0}$ (see Figure 2 ) is assumed equal to 1.50 ;

3. Only $\mathrm{S}$ failures are observed for $\mathrm{x}$ higher than or equal to 13. Hence, $\mathrm{x}_{2}$ (see Fig. 2) is assumed equal to 13 .

The best performance set of membership functions is obtained if $x_{1}$ (see Figure 2 ) is assumed equal to 3.1, if $f_{1}$ (see Figure 2) is assumed equal to 0.07 and if $s_{1}$ (see Figure 2) is assumed equal to 0.09 . With these assumptions, in fact, a correct prediction of the failure mode (i.e., the more possible failure mode corresponds with the actual failure mode) is obtained in $84 \%$ of cases. Note that the values of $\mathrm{x}_{00}, \mathrm{x}_{0}, \mathrm{x}_{2}, \mathrm{x}_{1}, \mathrm{f}_{1}$, and $\mathrm{s}_{1}$ are different with respect to those shown in [20] since they were evaluated with respect to a smaller database.

The obtained membership functions are shown in Figure 3 and compared with the experimental failure modes. Experimental failure modes are reported as filled circles if they are predicted as the most possible failure mode by the adopted membership functions; otherwise, they are reported as blank circles.

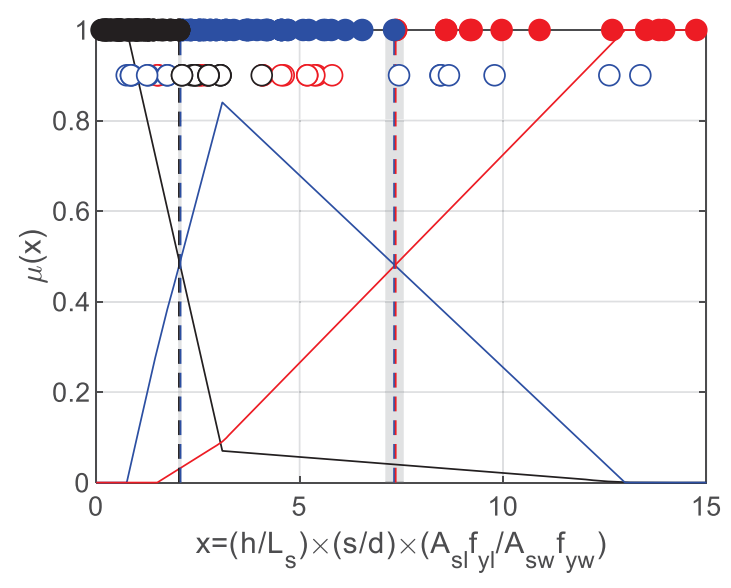

(a)

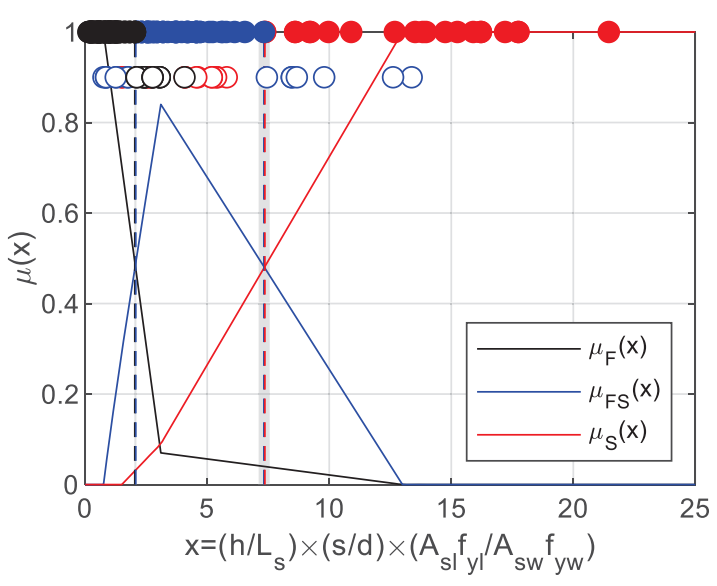

(b)

Figure 3: Adopted membership functions. Graph with $\mathrm{x}$ between 0 and 15 (a) and graph with $\mathrm{x}$ between 0 and 25 (b). 
It is possible to observe that for $\mathrm{x}$ lower than 2 the most possible failure mode is $\mathrm{F}$; for $\mathrm{x}$ between 2 and 7.3 the most possible failure mode is FS; for $\mathrm{x}$ higher than 7.3, the most possible failure mode is $\mathrm{S}$. It is worth recalling that for $\mathrm{x}$ lower than 0.75 the only possible failure mode is $\mathrm{F}$, while for $\mathrm{x}$ higher than 13 the only possible failure mode is $\mathrm{S}$. It is also worth mentioning that for $\mathrm{x}$ between 2 and 2.1 and for $\mathrm{x}$ between 7.1 and 7.6 there is no failure mode with possibility of occurrence higher than 50\%: special caution should be adopted when dealing with structural members belonging to these "transition zones" (grey-filled areas in Figure 3).

\section{BASIC RESPONSE ENVELOPE}

In this section, the basic bending moment $\mathrm{M}$ - chord rotation $\theta$ response envelope is determined for ductile members, i.e., for RC columns with x lower than or equal to 0.75 .

\subsection{Response envelope and methodology}

Based on the response envelope of the experimental response of ductile members included in the database, the following characteristic points/conditions were defined.

- The first point of the proposed envelope is yielding point. First, a theoretical prediction of $\mathrm{M}_{\mathrm{y}}$ was obtained by means of a fibre section analysis and indicated as $\mathrm{M}_{\mathrm{y} \text {,fiber. }}$. Then, the experimental maximum moment $\mathrm{M}_{\max }$ was determined. If $\mathrm{M}_{\max }$ resulted higher than $1.07 \mathrm{M}_{\mathrm{y}}$,iber, the yielding point was identified on the experimental envelope at the attainment of $\mathrm{M}$ equal to $\mathrm{M}_{\mathrm{y}, \text { fiber; }}$ otherwise, according to [21], the yielding point was identified on the experimental envelope at the attainment of $\mathrm{M}$ equal to $0.80 \mathrm{M}_{\max }$;

- The second point of the envelope is the peak load point. It was simply determined at the attainment of a moment equal to the maximum moment $M_{\max }$.

- The third point of the envelope was determined on the descending branch of the experimental response envelope at the attainment of a moment equal to $0.80 M_{\max }$. This point corresponds to the attainment of a conventional "ultimate" condition.

- The fourth and last point of the envelope is the one corresponding to the complete loss of lateral load capacity of the column. It was determined, on the experimental envelope, by linear extrapolation up to zero moment resistance of the extreme points of the imposed displacement cycles defining the descending branch of the experimental envelope beginning from the experimental point at conventional "ultimate", as defined at the previous point. Note that, to limit the use of unreliable extrapolated data, only tests for which at least a 50\% strength decrease after peak load point attainment were considered for the assessment of this point.

A consistent approach was adopted to define an equivalent set of predictive equations for the assessment of the response envelope of rectangular RC column with plain bars in [22].

The following parameters were adopted to identify the abovementioned characteristic points of the response envelope, as shown in Figure 4.

- The ratio between the flexural secant stiffness at yielding of the member cross-section (also called "effective stiffness"), $E I_{y}$, and the flexural stiffness of the gross section $E I_{g}$. This ratio allows defining, together with the yielding moment $M_{y}$ previously defined, the chord rotation at yielding, $\theta_{y}$;

- The maximum moment $\mathrm{M}_{\max }$ together with the corresponding post-yielding plastic chord rotation, $\theta_{\max }{ }^{p l}$; 
- The post-capping plastic chord rotation at conventional "ultimate" condition, $\theta_{u l}{ }^{p c}$;

- The post-ultimate plastic chord rotation at the attainment of zero lateral load capacity, $\theta_{0}{ }^{p u}$, together with the softening stiffness toward zero lateral load capacity, $K_{0}$.

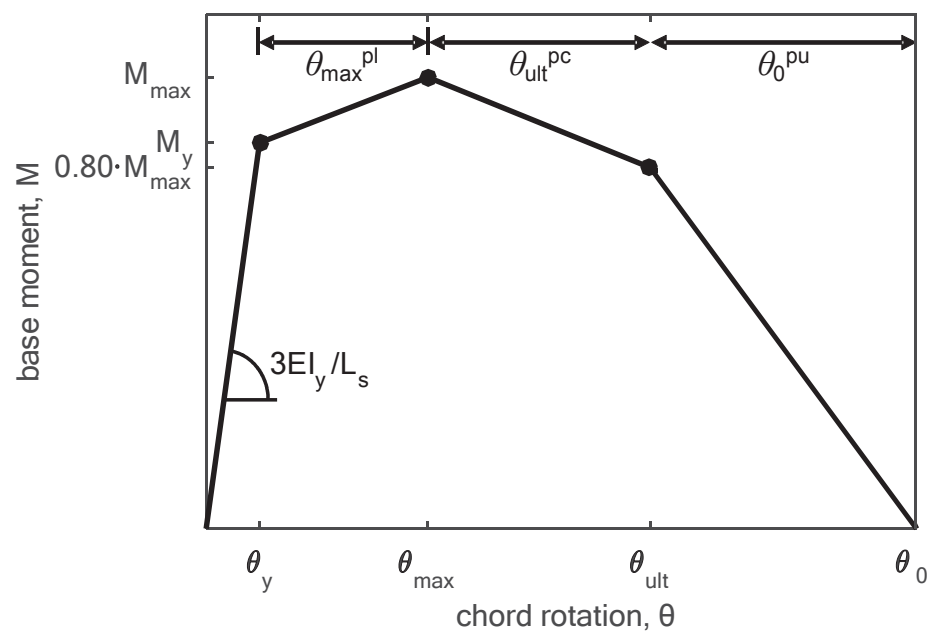

Figure 4: Characteristic points and assumed parameters of the base moment $(\mathrm{M})$ - chord rotation $(\theta)$ response envelope.

In order to define empirical formulations for the prediction of the abovementioned response parameters, some potential predictors were selected. The candidate predictors were chosen by considering the outcomes of past studies (e.g., [23]), as well as their expected mechanical influence. In addition to those listed for the description of the experimental database (see section 2), some combinations of them were assumed as potential predictive parameters, namely:

- the ratio between the spacing of transverse reinforcement, $s$, and the cross-section depth, $\mathrm{d}$;

- the ratio between the spacing of transverse reinforcement, s, and the diameter of longitudinal rebars, $\mathrm{d}_{\mathrm{b}}$;

- a factor related to the proneness to buckling of longitudinal bars, $\mathrm{s}_{\mathrm{n}}=\left(\mathrm{s} / \mathrm{d}_{\mathrm{b}}\right) \cdot\left(\mathrm{f}_{\mathrm{y}} / 100\right)^{0.5}$;

- the area/mechanical ratio of longitudinal rebars $\rho_{1}$ and $\omega_{1}$;

- the area/mechanical ratio of transverse reinforcement $\rho_{\mathrm{w}}$ and $\omega_{\mathrm{w}}$;

- the longitudinal reinforcement area/mechanical ratio calculated by separating the contribution of reinforcement in compression ( $\rho_{2}$ and $\omega_{2}$, respectively) from the contribution of reinforcement in tension + web reinforcement ( $\rho_{1}$ and $\omega_{1}$, respectively);

- the ratio between the area/mechanical longitudinal reinforcement ratio for rebars in compression and the mechanical longitudinal reinforcement ratio for rebars in tension.

The statistical procedure adopted for defining the predictive equations below listed is described in detail in [24]. More specifically, linear least squares regressions were performed relating the output variables (expressed in terms of natural logarithm) and the potential predictors (expressed in their natural form, in terms of natural logarithm, or absent). The final equations proposed were selected among the ones with the minimum number of input variables but deemed as "statistically equivalent" - based on F-tests - to the basic predictive equations including all the potential predictors. For the assessment of predictive equations, T-tests were performed to remove outliers from the experimental database [25]. 


\subsection{Predictive equations}

The equations derived to define the response envelope of ductile rectangular RC columns with deformed bars are reported below, together with, for each proposed equation, the statistics - mean, median and Coefficient of Variation $(\mathrm{CoV})$ - associated with the set of the observed value-to-predicted value ratios for the entire experimental database. In the proposed equations, forces must be expressed in Newtons and lengths in millimetres.

The ratio between secant-to-yielding and gross section stiffness, $\mathrm{EI} / \mathrm{EI}_{\mathrm{g}}$ can be calculated as reported in Equation 2 (observed-to-predicted ratio: mean=1.09, median=1.00, $\mathrm{CoV}=0.42$ ).

$$
E I_{y} / E I_{g}=0.0318 \cdot 6.11^{v} \cdot\left(L_{s} / d\right)^{1.21}
$$

Alternatively, the ratio between secant-to- $40 \%$ of yielding moment and gross section stiffness, $\mathrm{EI}_{40} / \mathrm{EI}_{\mathrm{g}}$ can be calculated as reported in Equation 3 (observed-to-predicted ratio: mean $=1.13$, median $=0.99, \mathrm{CoV}=0.49)$.

$$
E I_{40} / E I_{g}=0.100 \cdot 3.20^{v} \cdot\left(L_{s} / d\right)^{0.871}
$$

Note that both Equations 2 and 3 were obtained by considering not only F, but also FS specimens included in the database.

The post-yielding plastic chord rotation, $\theta_{\max }{ }^{\mathrm{pl}}$ can be calculated as reported in Equation 4 (observed-to-predicted ratio: mean $=1.15$, median $=0.97, \mathrm{CoV}=0.54$ ). Note that for the assessment of $\theta_{\max }{ }^{\mathrm{pl}}$ some tests were not considered since their response envelope was provided with a branch at pseudo-constant moment demand roughly equal to the maximum moment. In these cases, the value of the chord rotation at peak load was not determinable in a unique and not ambiguous way.

$$
\theta_{\max }^{p l}=0.0073 \cdot 0.436^{v} \cdot(s / d)^{-0.261} \cdot 1.05^{100 \omega_{2}}
$$

For the calculation of the peak resistance, $\mathrm{M}_{\max }$, a simple mean value is proposed attempting to predict the $\mathrm{M}_{\max } / \mathrm{M}_{\mathrm{y}}$ ratio, i.e., $\mathrm{M}_{\max } / \mathrm{M}_{\mathrm{y}}=1.31$ (observed-to-predicted ratio: $\mathrm{CoV}=0.15$ ), with $\mathrm{M}_{\mathrm{y}}$ calculated by means of a section fibre analysis.

The post-capping "ultimate" plastic chord rotation, $\theta_{\text {ult }}^{\text {pc }}$ can be calculated as reported in Equation 5 (observed-to-predicted ratio: mean $=1.16$, median $=0.99, \mathrm{CoV}=0.58$ ).

$$
\theta_{u l t}^{p c}=0.0126 \cdot 0.161^{v} \cdot 5.66^{\omega_{l}} \cdot 1.88^{100 \rho_{w}}
$$

The post-ultimate plastic chord rotation towards zero resistance, $\theta_{0}{ }^{\mathrm{pu}}$ can be calculated as reported in Equation 6 (observed-to-predicted ratio: mean $=1.11$, median $=1.16, \mathrm{CoV}=0.42$ ). It is limited to the maximum value of $\theta_{0}{ }^{\mathrm{pu}}$ observed in the database.

$$
\theta_{0}^{p u}=\min \left(0.065 ; 0.0193 \cdot 0.061^{v} \cdot 1.19^{100 \omega_{w}}\right)
$$

To avoid modelling issues, namely to avoid that the bilinear softening branch of the response envelope is characterized by decreasing (in absolute value) softening stiffness, the post-ultimate plastic chord rotation resulting from Equation 6 must be further limited according to Equation 7.

$$
\theta_{0}^{p u} \leq 4 \theta_{u l t}^{p c}
$$

\subsection{Application}

The comparison of the outcomes of proposed model for ductile RC members with six experimental responses included in the experimental database (the three specimens with the "best" performance of the proposed model and the three specimens with the "worst" performance of 
the proposed model) is shown in Figure 5, together with the cyclic envelope calculated by applying the model by [23]. The best performance of the proposed model is obtained for specimens C5-00N tested in [26], C1-1 tested in [27] and Test1 tested in [28] while the worst performance is observed for specimens No.7 tested in [29], 214-08 tested in [30], and HC48L19-T10-0.1P tested in [31].
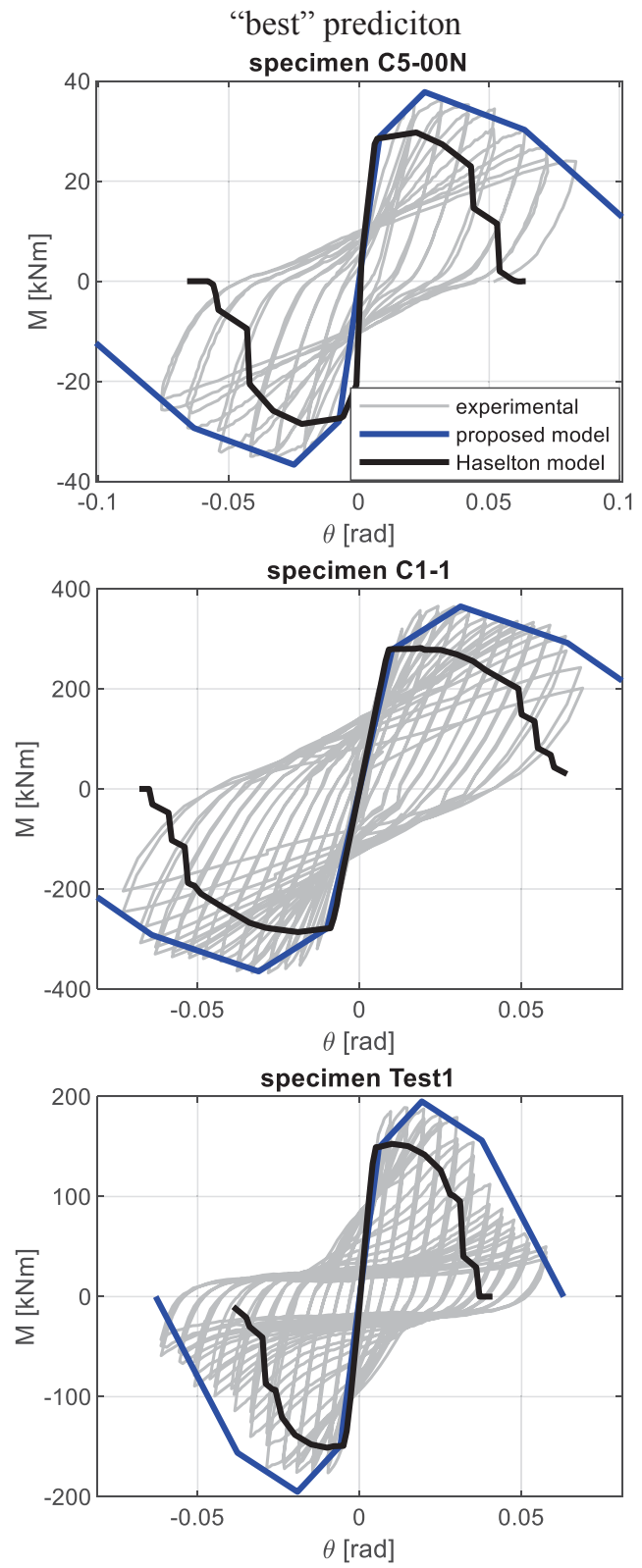
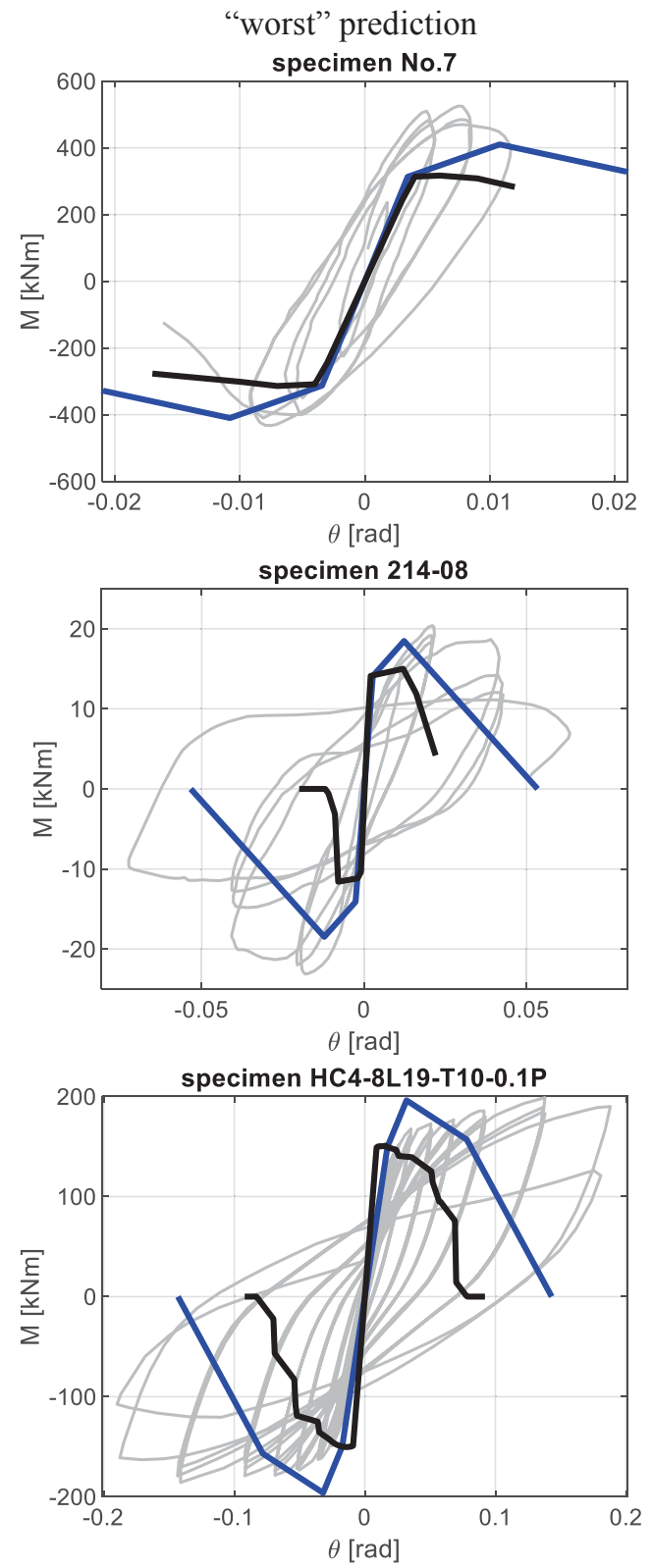

Figure 5: "Best" (left column) and "worst" (right column) predictions of the proposed model compared with the experimental response of the selected specimens and with the cyclic envelope predicted by applying the model proposed by Haselton et al. [23].

Since it was determined based only on cyclic tests, the proposed model already includes in its envelope the sources of strength degradation typical of members under cyclic (such as seismic) loading. On the contrary, the response envelope proposed by Haselton et al. [23] is monotonic, as it is based on the results of monotonic tests and on the expected monotonic envelope derived from a back-analysis of the results of cyclic tests. The cyclic envelope shown in Figure 5 as a 
result of the application of the model by Haselton et al. is obtained by modelling the specimen in OpenSees [32] by adopting ModIMKPeakOriented Material model and by applying to it the real imposed displacement path. In general, it was observed that the model by Haselton et al. can show a fast decay of strength capacity, both in terms of maximum moment capacity and in terms of steepness of the softening branch when the imposed displacement path is characterized by a significant number of loading-unloading cycles. On the other hand, the proposed model seems to not predict well the cyclic response envelope when the maximum moment capacity is significantly higher than yielding moment and, in tune, the chord rotation at maximum is significantly higher than the chord rotation at yielding.

\section{CONCLUSIONS AND FUTURE DEVELOPMENTS}

- A subset of ACI 369 database of experimental tests on rectangular RC columns with deformed longitudinal rebars [12] has been selected. The selected tests were cyclic and realized on columns without lap-sliced anchorage of longitudinal rebars. In addition, they are characterized by different failure modes assessed independently on a specific shear strength model: namely, 156 tests are classified as F (60\% of the database), 69 tests are classified as FS (26\% of the database), 35 tests are classified as S (14\% of the database).

- Based on the experimental database collected, a "continuous" approach for the assessment of the expected failure mode has been proposed. In fact, a single predictor parameter has been identified depending only on geometric and mechanical properties of the RC element. Based on this predictor, named $\mathrm{x}$, membership functions are proposed to calculate the possibility (a number between 0 and 1) that the considered member exhibits an F, and FS or an $\mathrm{S}$ failure. RC members with $\mathrm{x}$ lower than or equal to 0.75 are expected to exhibit only an $\mathrm{F}$ failure mode, while members with $\mathrm{x}$ greater than 13 are expected to exhibit only an $\mathrm{S}$ failure mode. The proposed approach can correctly predict as most possible the actual failure mode of the specimens included in the database in $84 \%$ of cases.

- For RC members with x lower than or equal to 0.75 , i.e., for expected ductile RC members, a set of predictive equations have been proposed to assess their cyclic moment - chord rotation response envelope up to the complete loss of lateral load resistance. This set of equations can be useful for modelling RC members, within a lumped plasticity approach, for collapse risk assessment of RC structures via nonlinear analyses.

- In the literature, a similar model with the same aims was already proposed by Haselton et al. [23]. However, it was observed that the cyclic response envelope predicted by applying this model may be affected by premature decay of strength capacity when the RC element is subjected by a significant number of loading-unloading cycles. In addition, the equations proposed by Haselton et al. [23] can predict only the expected monotonic envelope of the $\mathrm{RC}$ element, while the cyclic envelope including strength and stiffness degradation effects typical of seismic action can be determined only by applying to the RC member the real imposed displacement path. This makes the model by Haselton et al. [23] unfit for the assessment of RC structures via nonlinear static analysis, which is still a useful tool adopted by practitioners and researchers, especially for the assessment of existing buildings.

- In future works, the proposed equations for the assessment of the cyclic response envelope will be combined with the proposed membership functions in order to make them applicable for the evaluation of the expected response envelope for RC members with whichever 
failure mode and, above all, without the necessity of pre-determining the expected failure mode. In addition, the parameters for modelling the cyclic degradation of unloading and reloading stiffness, as well as the so-called "pinching" effect will be calibrated.

\section{ACKNOWLEDGMENTS}

This work was developed under the financial support of ReLUIS-DPC 2019-2021 funded by the Italian Department of Civil Protection (DPC). This support is gratefully acknowledged.

\section{REFERENCES}

[1] M.J.N. Priestley, R. Verma, Y. Xiao, Seismic shear strength of reinforced concrete columns. Journal of Structural Engineering, 120(8), 2310-239, 1994.

[2] Applied Technology Council (ATC), Seismic design guidelines for highway bridges (ATC-6). Berkeley, California, United States of America, 1981.

[3] P. Ricci, V. Manfredi, F. Noto, M. Terrenzi, M.T. De Risi, M. Di Domenico, G. Camata, P. Franchin, A. Masi, F. Mollaioli, E. Spacone, G.M. Verderame GM, RINTC-e: Towards seismic risk assessment of existing residential reinforced concrete buildings in Italy. 7 th ECCOMAS Thematic Conference on Computational Methods in Structural Dynamics and Earthquake Engineering. June 24-26, Crete, Greece, 2019.

[4] L. Zhu, K.J. Elwood, T. Haukaas T, Classification and seismic safety evaluation of existing reinforced concrete columns. Journal of Structural Engineering, 133 (9), 1316-1330, 2007.

[5] H. Sezen, J.P. Moehle, Shear strength model for lightly reinforced concrete columns. Journal of Structural Engineering, 130 (11), 1692-1703, 2004.

[6] W.M. Ghannoum, A.B. Matamoros, Nonlinear modelling parameters and acceptance criteria for concrete columns. ACI Special Publication, 297, 1-24, 2014.

[7] W.M. Ghannoum, Re-evaluation of modeling parameters and acceptance criteria for nonductile and splice-deficient concrete columns. 16th World Conference on Earthquake Engineering. January 9-13, Santiago, Chile, 2017.

[8] American Society of Civil Engineers/Structural Engineering Institute (ASCE/SEI) Committee 41 (2014): Seismic evaluation and retrofit of existing buildings (ASCE/SEI 41-13). Reston, Virginia, United States of America.

[9] American Society of Civil Engineers/Structural Engineering Institute (ASCE/SEI) Committee 41 (2017): Seismic evaluation and retrofit of existing buildings (ASCE/SEI 41-17). Reston, Virginia, United States of America.

[10] J. Hua, M.O. Erberhard, L.N. Lowes, X. Gu, Modes, mechanisms, and likelihood of seismic shear failure in rectangular reinforced concrete columns. Journal of Structural Engineering, 145 (10), 2019.

[11] Y. Ma, J.X. Gong, Probability identification of seismic failure modes of reinforced concrete columns based on experimental observations. Journal of Earthquake Engineering, 22 (10), 1881-1899, 2018. 
[12] B. Sivaramakrishnan, Non-linear modeling parameters for reinforced concrete columns subjected to seismic loads. The University of Texas at Austin. PhD Dissertation, 2010.

[13] M. Berry, M. Parrish, M. Eberhard, PEER Structural Performance Database: User's Manual, Version 1.0. Pacific Earthquake Engineering Research Center, University of California, Berkeley, CA, USA, 2004.

[14] M. Melek, J.W. Wallace, Cylic Behavior of Columns with Short Lap Splices. ACI Structural Journal, 101(6), 802-811, 2004.

[15] D.E. Biskinis, G.K. Roupakias, M.N. Fardis, Degradation of shear strength of reinforced concrete members with inelastic cyclic displacement. ACI Structural Journal, 101(6), 773-83, 2004.

[16] C. Del Vecchio, M. Del Zoppo, M. Di Ludovico, G.M. Verderame, A. Prota, Comparison of available shear strength models for non-conforming reinforced concrete columns. Engineering Structures, 148, 312-327, 2017.

[17] D.K. Zimos, P.E. Mergos, A.J. Kappos, Modelling of R/C members accounting for shear failure localisation: Hysteretic shear model. Earthquake Engineering and Structural Dynamics, 47, 1722-1741, 2018.

[18] L.A. Zadeh, Fuzzy sets. Information and Control, 8(3), 338-353, 1965.

[19] L.A. Zadeh, Fuzzy sets as a basis for a theory of possibility. Fuzzy Sets and Systems, 1, 3-28, 1978 .

[20] M. Di Domenico, P. Ricci, G.M. Verderame GM, Towards a deformation capacity assessment of flexure- and shear-sensitive RC members with a unified approach. $17^{\text {th }}$ World Conference on Earthquake Engineering. September 13-18, Sendai, Japan, 2020.

[21] K.J. Elwood, M. Eberhard, Effective stiffness of reinforced concrete columns. ACI Structural Journal, 106(4), 476-484, 2009.

[22] M. Di Domenico, P. Ricci, G.M. Verderame, Empirical calibration of hysteretic parameters for modeling the seismic response of reinforced concrete columns with plain bars. Engineering Structures, XX, 2021.

[23] C.B. Haselton, A.B. Liel, S. Taylor-Lange, G.G. Deierlein, Beam-column element model calibrated for predicting flexural response leading to global collapse of RC frame buildings. PEER Report No. 2007/03. Pacific Earthquake Engineering Research Center, University of California, Berkeley, CA, USA, 2008.

[24] G.M. Verderame, P. Ricci, An empirical approach for nonlinear modeling and deformation capacity assessment of RC columns with plain bars. Engineering Structures, 176, 539-554, 2018.

[25] B. Rosner, Percentage Points for a Generalized ESD Many-Outlier Procedure, Technometrics, 25(2), 165-172, 1983.

[26] A.B. Matamoros, Study of Drift Limits for High-Strength Concrete Columns. Department of Civil Engineering. Urbana (Illinois); University of Illinois at Urbana-Champaign. Doctor of Philosophy: 484, 1999.

[27] Y.L. Mo, S.J. Wand, Seismic Behavior of RC Columns with Various Tie Configurations. Journal of Structural Engineering, 126(10), 1122-1130, 2000. 
[28] H.K. Takemura, K. Kawashima, Effect of Loading Hysteresis on Ductility Capacity of Reinforced Concrete Bridge Piers. Proceedings of Structural Engineering (Japan Society of Civil Engineers), 43(A), 849-858, 1997.

[29] S. Watson, Design of Reinforced Concrete Frames of Limited Ductility. Department of Civil Engineering. Christchurch; New Zealand; University of Canterbury. Doctor of Philosophy: 248, 1989.

[30] X. Zhou, T. Satoh, W. Jiang, A. Ono, Y. Shimizu, Behavior of Reinforced Concrete Short Column Under High Axial Load. Transactions of the Japan Concrete Institute, 9, 541548, 1987.

[31] Y. Xiao, A. Martirossyan A, Seismic Performance of High-Strength Concrete Columns. Journal of Structural Engineering, 124(3): 241-251, 1998.

[32] F. McKenna, G.L. Fenves, M.H. Scott, OpenSees: Open System for Earthquake Engineering Simulation. Pacific Earthquake Engineering Research Center. University of California, Berkeley, CA, USA, 2004. 